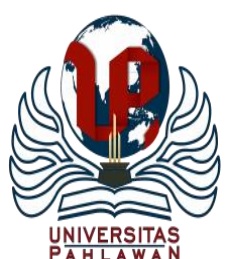

Jurnal Abdidas Volume 2 Nomor 4 Tahun 2021 Halaman 866-870

JURNAL ABDIDAS

http://abdidas.org/index.php/abdidas

\title{
Penyuluhan Tentang Bahaya Merokok Bagi Kesehatan Remaja Di LKP Universal Technology Computer
}

\author{
Riri Safitri \\ Institut Kesehatan Medistra Lubuk Pakam, Indonesia \\ E-mail : ririsafitribiologi@gmail.com
}

\begin{abstract}
Abstrak
Perilaku remaja berdampak negatif yang sering terlihat saat sekarang ini salah satunya yaitu merokok. Merokok yang biasanya merupakan perilaku yang dilakukan oleh orang dewasa, namun sekarang ini, para remaja pun sudah banyak yang mencoba untuk merokok. Dari data yang diperoleh tentang meningkatnya konsumsi rokok yang dilakukan oleh para remaja, oleh karena itu penelitian melakukan penyuluhan tentang bahaya merokok bagi kesehatan di Lembaga Kursus Pelatihan Universal Technology Computer. Metode pelaksanaan yang dipakai yaitu dengan metode ceramah dengan mengikuti aturan prokol kesehatan yang telah ditentukan. Kegiatan dilakukan dalam beberapa tahapan antara lain tahap pertama yaitu membagikan kuesioner pengetahuan dan sikap (pre-test). Tahap kedua yaitu memberikan penyuluhan tentang bahaya merokok bagi kesehatan kepada para peserta. Pada akhir kegiatan dibagikan kuesioner pengetahuan dan sikap (post-test). Hasil penyuluhan yang dilakukan menunjukkan bahwa dengan mengikuti penyuluhan peserta penyuluhan memperoleh tambahan wawasan yang lebih banyak lagi serta sikap yang lebih baik lagi. Dengan demikian kedepannya para peserta tersebut tidak mudah terpengaruh dengan ajakan dari berbagai sumber yang dapat mempengaruhi peserta dalam mengkonsumsi rokok.
\end{abstract}

Kata kunci: penyuluhan, bahaya merokok, remaja

\section{Abstract}

Adolescent behavior has a negative impact that is often seen today, one of which is smoking. Smoking is usually a behavior carried out by adults, but nowadays, many teenagers have tried to smoke. From the data obtained about the increasing consumption of cigarettes by teenagers, therefore I conducted counseling about the dangers of smoking to health at the Universal Technology Computer Training Course Institute. The implementation method used is the lecture method by following the health protocol rules that have been determined. The activity was carried out in several stages, including the first stage, namely distributing knowledge and attitude questionnaires (pre-test), the second stage, namely providing counseling about the dangers of smoking for health to the participants. At the end of the activity, knowledge and attitude questionnaires were distributed (post-test). The results of the counseling carried out showed that by participating in the counseling participants received more additional insights and even better attitudes. Thus in the future the participants are not easily influenced by invitations from various sources that can influence participants in consuming cigarettes.

Keywords: counseling, dangers of smoking, teens

Copyright (c) 2021 Riri Safitri

$\triangle$ Corresponding author

Address : Institut Kesehatan Medistra Lubuk Pakam

Email : ririsafitribiologi@gmail.com

DOI : $\quad$ https://doi.org/10.31004/abdidas.v2i4.385

ISSN 2721- 9224 (Media Cetak)

ISSN 2721- 9216 (Media Online) 
867 Penyuluhan Tentang Bahaya Merokok Bagi Kesehatan Remaja Di LKP Universal Technology Computer - Riri Safitri

DOI: https://doi.org/10.31004/abdidas.v2i4.385

\section{PENDAHULUAN}

Perilaku remaja berdampak negatif yang sering terlihat saat sekarang ini salah satunya yaitu merokok. Merokok yang biasanya merupakan perilaku yang dilakukan oleh orang dewasa, namun sekarang ini, para remaja pun sudah banyak yang mencoba untuk merokok. Sesuai dengan (Awaluddin \& Destya Rahmani, 2013) menyatakan bahwasanya merokok merupakan sebuah aktivitas yang kini banyak di gandrungi oleh para remaja kita. Dahulu kala merokok hanyalah menjadi bagian dari kehidupan orang orang tua. Tapi kini merokok sudah merambah ke dalam kehidupan anak-anak sekolah. Menurut (WHO, 2020) survei berbagai kelompok umur di Indonesia dari tahun ke tahun menunjukkan tren peningkatan penggunaan tembakau di kelompok anak dan remaja. Riset Kesehatan Dasar 2018 menunjukkan prevalensi merokok di kelompok usia 10-19 tahun melonjak dari 7,2\% pada tahun 2013 hingga 9,1\% pada tahun 2018, hampir 20\% lebih tinggi dibandingkan prevalensi lima tahun sebelumnya.

Merokok dapat membahayakan kesehatan si perokok maupun orang yang disekitarnya. Menurut (Prihatiningsih et al., 2020) Rokok merupakan salah satu faktor resiko utama dari beberapa penyakit kronis yang dapat mengakibatkan kematian. Hal ini menunjukkan bahwa rokok merupakan masalah besar bagi kesehatan masyarakat. Selain dari segi kesehatan, rokok juga mempengaruhi kepribadian perokok itu sendiri. Selanjutnya Menurut (Giemza, 2004) Perokok jangka panjang kehilangan setidaknya 10 tahun kehidupan mereka. Di tingkat global, lebih dari 22,000 orang meninggal dunia karena penggunaan tembakau atau terpapar asap rokok setiap harinya - satu orang dalam 4 detik setiap harinya. Penggunaan tembakau memengaruhi hampir semua organ tubuh manusia. Adapun beberapa penyakit yang ditimbulkan akibat asap rokok antara lain kanker paru-paru, asma, penyakit paru obstruktif kronis, tuberkulosis, penyakit pernafasan lainnya dan menurunnya fungsi paru, kanker mulut dan penyakit lainnya.

Dari data yang diperoleh tentang meningkatnya konsumsi rokok yang dilakukan oleh para remaja, oleh karena itu saya melakukan penyuluhan tentang bahaya merokok bagi kesehatan di Lembaga Kursus Pelatihan Universal Technology Computer, dengan tujuan memberikan pengetahuan dan meningkatkan kesadaran kepada para remaja yang belajar di lembaga tersebut agar tidak merokok dan berhenti merokok bagi remaja yang sudah terlanjur konsumsi rokok.

\section{METODE}

Kegiatan pengabdian kepada masyarakat dimulai dengan melakukan permohonan ijin kepada pengelola lembaga kursus Universal Technology Computer, setelah mengajukan permohonan ijin maka pada tanggal 11 Februari 2021, kami melakukan pelaksanaan pengabdian masyarakat dengan judul "Penyuluhan Tentang Bahaya Merokok Bagi Kesehatan". Adapun metode pelaksanaan yang dipakai yaitu dengan metode ceramah dengan mengikuti aturan prokol kesehatan yang telah ditentukan. Jumlah peserta yang memperoleh Penyuluhan ini berjumlah 20 peserta. 
Kegiatan dilakukan dalam beberapa tahapan antara lain tahap pertama yaitu membagikan kuesioner pengetahuan dan sikap (pre-test), dengan tujuan untuk mengetahui pengetahuan dan sikap peserta sebelum diberikan penyuluhan mengenai bahaya merokok. Tahap kedua yaitu memberikan penyuluhan tentang bahaya merokok bagi kesehatan kepada para peserta. Pada akhir kegiatan dibagikan kuesioner pengetahuan dan sikap (post-test) yang tujuannya untuk mengevaluasi pengetahuan dan sikap peserta setelah diberikan penyuluhan.

\section{HASIL DAN PEMBAHASAN}

\section{Tahap Pertama}

Peserta penyuluhan diberikan kuesioner pratest pengetahuan dan sikap.

Tabel 1. Hasil Evaluasi Kuesioner Pra-test

\begin{tabular}{llll}
\multicolumn{3}{c}{ Pengetahuan } \\
\hline No & $\begin{array}{l}\text { Klasifikasi } \\
\text { Penilaian } \\
\text { Kuesioner }\end{array}$ & $\begin{array}{l}\text { Jumlah } \\
\text { Peserta }\end{array}$ & \% Pencapaian \\
& & \\
\hline 1 & Rendah & 9 & 45 \\
2 & Sedang & 11 & 55 \\
3 & Tinggi & 0 & 0 \\
\hline
\end{tabular}

Berdasarkan Tabel 1. diatas bahwa hasil evaluasi penilaian kuesioner pra-test pengetahuan diperoleh klasifikasi penilaian kuisioner rendah sampai sedang. Peserta yang memiliki nilai rendah sebanyak 9 peserta (45\%), selanjutnya yang memiliki nilai sedang sebanyak 11 peserta (55\%). Hal tersebut menunjukkan bahwa hanya sebagian peserta saja yang sudah memiliki cukup informasi tentang bahaya merokok bagi kesehatan.
Tabel 2. Hasil Evaluasi Kuesioner Pra-test Sikap

\begin{tabular}{llll}
\hline No & $\begin{array}{l}\text { Klasifikasi } \\
\text { Penilaian } \\
\text { Kuesioner }\end{array}$ & $\begin{array}{l}\text { Jumlah } \\
\text { Peserta }\end{array}$ & $\begin{array}{l}\% \\
\text { Pencapaian }\end{array}$ \\
\hline 1 & Kurang & 10 peserta & 50 \\
2 & Cukup & 8 peserta & 40 \\
3 & Baik & 2 peserta & 10 \\
\hline
\end{tabular}

Berdasarkan Tabel 2. diatas menunjukkan bahwa hasil evaluasi kuesioner pra-test sikap peserta tergolong ada yang kurang, cukup, dan baik. Jumlah peserta yang tergolong kurang sebanyak 10 peserta (50\%), tergolong cukup sebanyak 8 peserta $(40 \%)$, tergolong baik hanya sebanyak 2 peserta (10\%). Hal ini menunjukkan bahwa sikap peserta terkait dengan pengetahuan atau wawasan peserta. Sehingga dari data persentase pencapaian hasil evaluasi pra-test pengetahuan dan sikap, peserta penyuluhan memerlukan tambahan informasi dan pemahaman tentang bahaya merokok bagi kesehatan.

\section{Tahap Kedua}

Pada tahap kedua peserta penyuluhan diberikan materi tentang bahaya merokok bagi kesehatan.

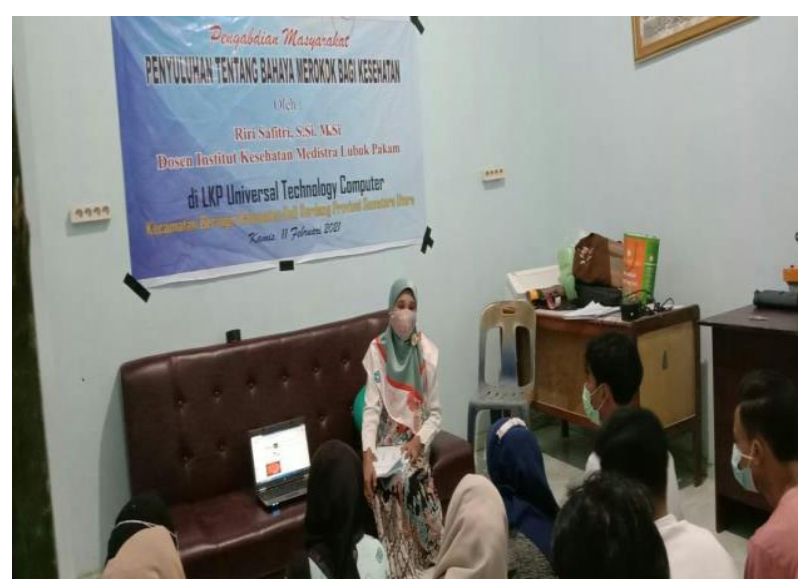

Gambar 1. Kegiatan Penyuluhan Tentang Bahaya Merokok Bagi Kesehatan 
Gambar 1. merupakan kegiatan penyuluhan tentang Bahaya Merokok Bagi Kesehatan yang dilakukan di Lembaga Kursus dan Pelatihan Universal Technologi Computer Desa Pasar V Kebun Kelapa Kecamatan Beringin Kabupaten Deli Serdang Provinsi Sumatera Utara. Pelaksanaan penyuluhan berjalan dengan tertib. Pada saat penyuluhan banyak peserta yang ikut aktif serta dalam tanya jawab secara lisan tentang materi yang disampaikan.

\section{Tahap Akhir}

Pada tahap akhir, peserta diberikan kuesioner post-test pengetahuan dan sikap.

Tabel 3. Hasil Evaluasi Kuesioner Post-test Pengetahuan

\begin{tabular}{llll}
\hline No & $\begin{array}{l}\text { Klasifikasi } \\
\text { Penilaian } \\
\text { Kuesinoner }\end{array}$ & $\begin{array}{l}\text { Jumlah } \\
\text { Peserta }\end{array}$ & $\begin{array}{l}\% \\
\text { Pencapa } \\
\text { ian }\end{array}$ \\
\hline $\mathbf{1}$ & Rendah & 0 peserta & 0 \\
$\mathbf{2}$ & Sedang & 13 peserta & 65 \\
\hline $\mathbf{3}$ & Tinggi & 7 peserta & 35 \\
\hline
\end{tabular}

Berdasarkan Tabel 3. diatas bahwa hasil evaluasi penilaian kuesioner post-test pengetahuan diperoleh klasifikasi penilai sedang dan tinggi. Peserta yang memiliki nilai sedang sebanyak 13 peserta (65\%), selanjutnya yang memiliki nilai tinggi sebanyak 7 peserta $(35 \%)$. Hal tersebut menunjukkan bahwa dengan mengikuti penyuluhan peserta penyuluhan memperoleh tambahan wawasan yang lebih banyak lagi. Dengan demikian kedepannya para peserta tersebut tidak mudah terpengaruh dengan ajakan dari berbagai sumber yang dapat mempengaruhi peserta dalam mengkonsumsi rokok.

Tabel 4. Hasil Evaluasi Kuesioner Post-test Sikap

\begin{tabular}{llll}
\hline No & $\begin{array}{l}\text { Klasifikasi } \\
\text { Penilaian } \\
\text { Kuesioner }\end{array}$ & $\begin{array}{l}\text { Jumlah } \\
\text { Peserta }\end{array}$ & \% Pencapaian \\
\hline 1 & Kurang & 0 peserta & 0 \\
2 & Cukup & 6 peserta & 30 \\
3 & Baik & 14 peserta & 70 \\
\hline
\end{tabular}

Dari Tabel 4. diatas bahwa hasil evaluasi kuesioner post-test sikap peserta tergolong cukup dan baik. Jumlah peserta tergolong cukup sebanyak 6 peserta (30\%), selanjutnya jumlah peserta tergolong baik sebanyak 14 peserta $(70 \%)$. Hal ini menunjukkan bahwa dengan diberikan penyuluhan, selain tambahan wawasan yang diperoleh, peserta juga menunjukkan sikap yang lebih baik. Sehingga terlihat ada hubungan antara pengetahuan dengan sikap peserta penyuluhan. Menurut (Wirawan, 2016) bahwa ada hubungan antara tingkat pengetahuan tentang bahaya merokok bagi kesehatan dengan tindakan merokok dan ada hubungan antara sikap tentang bahaya merokok bagi kesehatan dengan tindakan merokok.

Dari kegiatan penyuluhan yang dilakukan, diperoleh hasil yang sesuai dengan tujuan dari kegiatan penyuluhan yaitu untuk memberikan pengetahuan dan meningkatkan kesadaran kepada para remaja yang belajar di Lembaga LKP Universal Technology Computer agar tidak merokok dan berhenti merokok bagi remaja yang sudah terlanjur konsumsi rokok. 
870 Penyuluhan Tentang Bahaya Merokok Bagi Kesehatan Remaja Di LKP Universal Technology Computer-Riri Safitri

DOI: https://doi.org/10.31004/abdidas.v2i4.385

\section{SIMPULAN}

Penyuluhan tentang bahaya merokok bagi kesehatan yang dilakukan di LKP Universal Technology Computer Kecamatan Beringin menjadikan peserta penyuluhan memperoleh pengetahuan yang lebih luas dibandingkan sebelum penyuluhan serta perubahan sikap peserta menjadi jauh lebih baik dengan begitu para remaja tersebut tidak mudah terpengaruh dengan ajakan untuk konsumsi rokok serta berhenti merokok bagi remaja yang sudah terlanjur konsumsi rokok.

\section{UCAPAN TERIMA KASIH}

Penulis mengucapkan banyak terimakasih kepada seluruh pihak yang terkait dalam pelaksanaan kegiatan pengabdian masyarakat ini baik dari Institut Kesehatan Medistra Lubuk Pakam, pengelola LKP Universal Technology Computer dan seluruh peserta penyuluhan sehingga kegiatan ini dapat terlaksana dengan baik dan lancar.

\section{DAFTAR PUSTAKA}

Awaluddin, \& Destya Rahmani. (2013). Sosialisasi Bahaya Rokok Guna Meningkatkan Kesadaran Masyrarakat Yang Memiliki Dampak Buruk Rokok Bagi Kesehatan. Seri Pengabdian Masyarakat 2013 Jurnal, Volume 2 N(3), Halaman 224-232.

Giemza, M. (2004). The Tobacco Box. English, 53(207), 243-243. https://doi.org/10.1093/english/53.207.243a

Prihatiningsih, D., Devhy, N. L. P., Purwanti, I. S., Bintari, N. W. D., \& Widana, A. G. O. (2020). Penyuluhan Bahaya Rokok Untuk Meningkatkan Kesadaran Remaja Mengenai Dampak Buruk Rokok Bagi Kesehatan Di Smp Tawwakal Denpasar. Jurnal Pengabdian Kesehatan, 3(1), 50-58. https://doi.org/10.31596/jpk.v3i1.67
WHO. (2020). Menaikkan Harga Cukai dan Harga Produk Tembakau untuk Indonesia Sehat dan Sejahtera. 1--30.

Wirawan, A. S. (2016). Hubungan Antara Pengetahuan Dan Sikap Tentang Bahaya Merokok Bagi Kesehatan Dengan Tindakan Merokok Pelajar. Jurnal Keperawatan Dan Kesehatan MEDISINA AKPER YPIB Majalengka, II(3). 